NUTRITION KNOWLEDGE AND FOOD CONSUMPTION PRACTICES AND BARRIERS IN RURAL GHANA: THE CASE OF FOODS FOR PREVENTING VITAMIN A AND IRON DEFICIENCIES

\title{
Omari $\mathbf{R}^{1,2 *}$, Quorantsen $\mathrm{KE}^{2}$ and PK Omari ${ }^{2}$
}

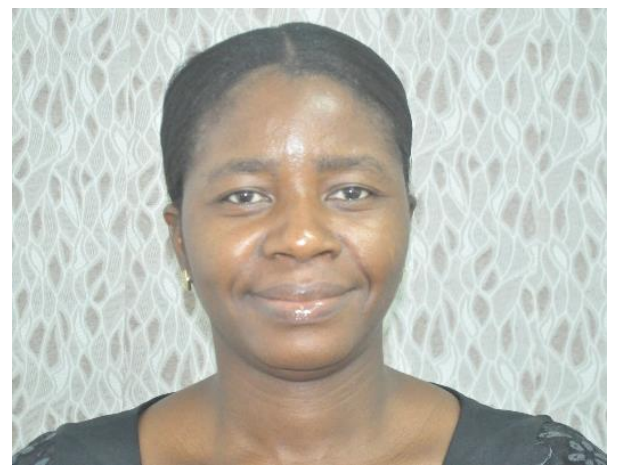

Rose Omari

*Corresponding author email: rose.omari@yahoo.com

${ }^{1}$ Science and Technology Policy Research Institute, P.O. Box CT 519, Cantonments, Accra, Ghana

${ }^{2}$ EatSafe Ghana, P.O. Box AN 7870, Accra-North, Ghana

${ }^{2}$ EatSafe Ghana, P.O. Box AN 7870, Accra-North, Ghana 


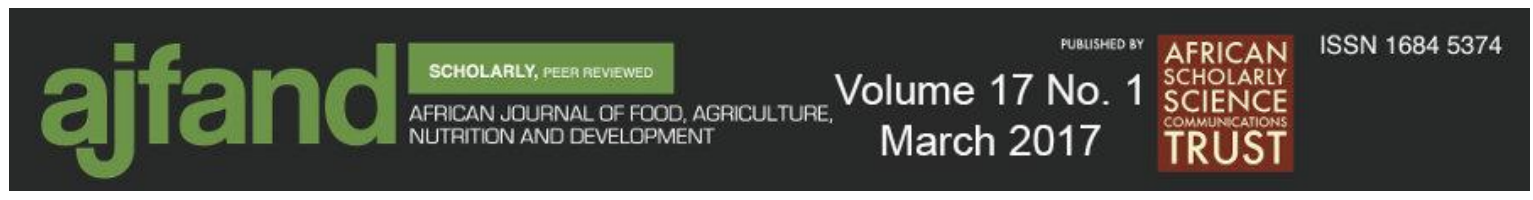

\begin{abstract}
Food-based approaches such as dietary diversification, nutrient retention and biofortification combined with nutrition education can be effective in eliminating micronutrient deficiencies. The objective of this study was to assess the nutrition knowledge and consumption practices as well as barriers to consumption with specific focus on food-based approaches to vitamin A and iron deficiencies prevention and to identify individual, community and governmental level strategies that may facilitate the adoption of these approaches. Using qualitative methods, one focus group (FG) discussion each was conducted with members of the Cocoa Farmers' Cooperatives in each of the 25 rural communities in the Amansie West and Asunafo North Districts in Ghana. Findings showed participants in only 3 FGs had knowledge of vitamin A and its deficiency diseases while only 2 FGs had knowledge of foods that could prevent vitamin A deficiency. Participants in 23 FGs were aware of the occurrence of iron deficiency anaemia especially in pregnant women; however, only 8 FGs had knowledge of the causes of anaemia. Furthermore, all the 25 FGs mentioned the use of haematinics in the treatment and prevention of anaemia but only 4 FGs knew about the use of food-based approaches. Various types of animal products, vegetables, fruits, and legumes, which are useful in preventing vitamin A and iron deficiencies, were found to be available in the communities. However, participants in all the 25 FGs indicated that the consumption of these foods particularly dark-green leafy vegetables has been dwindling with time. The FG participants mentioned a number of barriers to consumption of these foods and they include inadequate knowledge of nutritional value of the foods, lack of cooking skill, low production levels, laziness, conflicting media reports, lack of storage facilities, and contamination with agrochemicals. Findings imply that nutrition interventions should focus on education and awareness creation and implementation of strategies that can remove consumption barriers and facilitate the adoption of food-based approaches for managing micronutrient deficiencies.
\end{abstract}

Key words: Vitamin A deficiency, iron deficiency, nutrition knowledge, consumption practices, barriers 


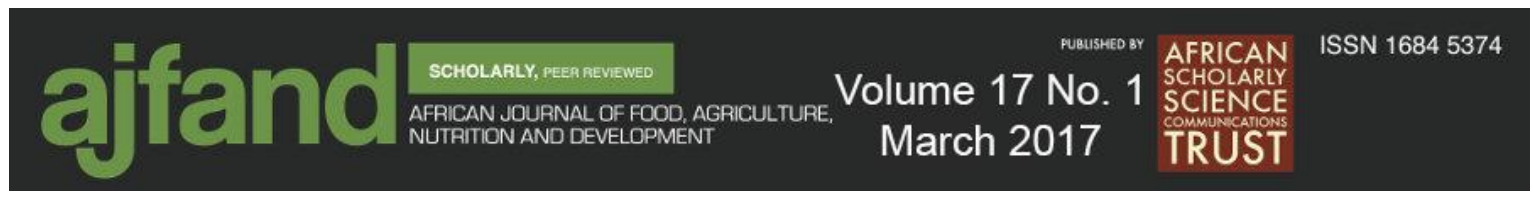

\section{INTRODUCTION}

Deficiencies of micronutrients, such as vitamin A and iron, are prevalent in most parts of Ghana. The main causes of vitamin A deficiency in Ghana are very low intake of foods of animal origin (for example, meat, eggs, dairy products), which contain high amounts of preformed retinol, and low intake of tubers, fruits, and vegetables rich in carotenoids [1]. Vitamin A deficiency can cause eye damage and can increase severity of infectious diseases such as measles [2]. The high prevalence of anaemia in Ghana is attributed to poor bioavailability of iron in the diet due to low intake of foods that enhance absorption of iron (for example, meat with vitamin C-rich foods) and health conditions such as malaria and intestinal worm infection $[1,2]$.

Prevalence of sub-clinical vitamin A deficiency was found to be very high $74 \%$ for children between 24 and 59 months) among Ghanaian children [3, 4]. Moreover, 35\% of children in this age group had severe vitamin A deficiency with serum retinol less than $10 \mu \mathrm{g} / \mathrm{dl}^{3}[3,4]$. Prevalence of anaemia among children under 5 years has reduced from $78 \%$ in 2008 to $66 \%$ in 2014 while that in women of reproductive age (15-49 years) reduced from 59\% in 2008 to $42 \%$ in 2014 [5,6]. However, these prevalence rates still exceed World Health Organization (WHO) maximum level of $40 \%$ making it a public health concern as it predisposes children to impaired mental and physical development and increased morbidity and mortality, and pregnant women to risk of low birth weight, birth defects, stillbirth, and even death [5, 6]. Also, anaemia among women and children is higher in rural areas $(51.8 \%)$ than urban areas $(48.2 \%)$ but decreases as mother's education and wealth increases [7].

Both vitamin A and iron deficiencies are considered major public health concerns; hence, currently, vitamin A deficiency is being reduced in Ghana by periodically (usually every 6 months) administering vitamin A supplements to children [5]. Measures being undertaken to reduce anaemia among vulnerable groups include iron and folic acid supplementation; anti-malaria prophylaxis for pregnant women; promotion and the use of insecticide-treated bed-nets by pregnant women and children under five; and sixmonth deworming for children 2-5 years since malaria and parasitic worms are also known causes of anaemia [6]. All these are proven, low-cost public health interventions for vitamin A and iron deficiencies; however, implementing them can be challenging because reaching the most vulnerable populations of women and children is difficult $[8$, 9].

There is, therefore, a recognized need for a fresh approach to action at the community level. One of the sustainable means of improving nutritional standards of rural communities is through food-based intervention strategies $[10,11]$. These include dietary diversity (encouraging consumption of different types of food to increase micronutrient intake), commercial fortification (adding fortificants to food during processing), nutrient retention (altering processing/cooking techniques to retain high nutrient levels at point of consumption), and biofortification (enriching the nutrient content of crops through agronomic techniques and conventional and transgenic breeding) [8]. Ghana government passed a legislative instrument in 2008 for mandatory fortification of all wheat flours with vitamin A, iron, folic acid, zinc, and B vitamins, and cooking oils with 


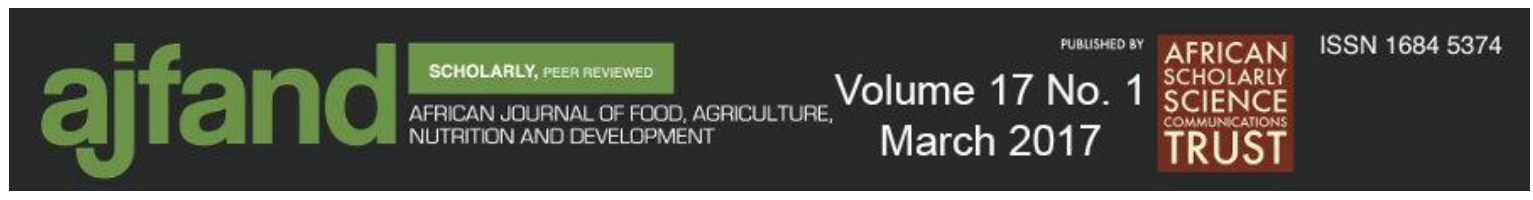

vitamin A but like most commercially fortified foods, they are often not readily accessible to rural populations [8].

Food-based approaches such as dietary diversification, nutrient retention including agriculture-sensitive interventions such as biofortification combined with extensive nutrition education offer a long-term strategy to control and eliminate micronutrient malnutrition $[10,12,13]$. However, the focus of Ghana's health sector has been curative care rather than preventive care until recently when the new National Health Policy was developed [2]. The policy emphasizes the importance of healthy eating, good nutrition, and more intensive and longer-term interventions such as growth promotion, health and nutrition education [2]. Unfortunately, however, intensive health and nutrition education with necessary inputs have not been delivered in Ghana on a scale large enough to bring desirable outcomes at the community or national level [14].

For successful outcomes of nutrition education and health promotion programmes, there is the need to understand various factors that promote or reduce consumption of the 'right' foods and integrate these into policies and programmes [15]. Therefore, the objective of this study is to assess the nutrition knowledge and consumption practices as well as barriers to consumption in rural cocoa-producing communities in Ghana with specific focus on food-based approaches to vitamin A and iron deficiencies prevention and to identify individual, community and governmental level strategies that may facilitate the adoption of these approaches. The study is particularly relevant because rural communities have poor access to good medical facilities and, therefore, need to be encouraged to use preventive measures to curb incidences of micronutrient deficiencies and to maintain good health for increased productivity.

\section{METHODOLOGY}

Twenty-five focus groups (FGs) (one per cocoa-producing community) were conducted with members of the Cocoa Farmers' Cooperatives from 11 cocoa-producing communities in the Amansie West District in the Ashanti Region and 14 communities in the Asunafo North District in the Brong Ahafo Region of Ghana. Focus groups were used to collect data because they supply descriptive, qualitative data that can be difficult to acquire through other research methods $[16,17]$. The FG discussions were conducted during a nutrition education campaign sponsored by Cadbury Cocoa Partnership Programme in 25 cocoa-producing communities where they operate.

Before the nutrition education started, 12 cooperative members (both male and female) were randomly selected in each community to participate in the focus group discussions. Each focus group session lasted for a maximum of two hours and the entire study was conducted for 15 days. Participants responded to questions posed by the group moderator. First of all, the moderator (a nutrition educator) asked participants to say what they know about vitamin A and iron, their deficiencies diseases, and how they can be prevented or treated. The moderator discussed Ghana's Ministry of Health recommended food groups for the prevention of vitamin A and iron deficiencies with the participants. The participants were then asked to identify specific food items in each food group that are available in their communities. Further discussions were held on the prevailing 


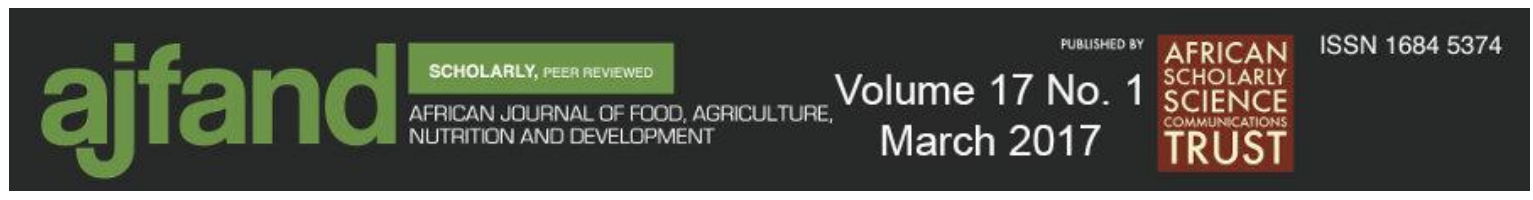

consumption practices of the identified foods and the barriers that limited their consumption. After this, participants were asked to discuss actions that could be taken at the individual, community or governmental levels to facilitate the adoption of food-based approaches to eliminate micronutrient deficiencies. The programme was conducted in Twi, a local Ghanaian language predominantly spoken in all the communities. Each FG discussion was tape-recorded, later transcribed and the transcripts were systematically reviewed by the authors.

\section{RESULTS}

\section{Description of participants}

In total, 300 participants (178 males and 122 females), who were mainly cocoa farmers but also grow food crops for commercial purposes and home consumption, took part in the study. The participants made up of $79 \%$ had no formal education and could neither read nor write, $20 \%$ had basic education, and $1 \%$ had secondary education. However, they were lively, very active, freely responded to questions, shared their problems and concerns, and contributed ideas that went a long way in clarifying issues. Both male and female participants freely shared their opinions- there was no obvious intimidation on the basis of gender.

\section{Nutrition knowledge, consumption practices, and suggested actions at the individual, community and governmental levels}

The key findings from all the 25 focus groups (FGs) are presented together because the content of the discussions were found to be similar.

\section{Participants' nutrition knowledge}

In this section, only responses made by at least two persons in a FG were considered. Findings showed that in all the 25 FGs, participants knew that food was important for energy, growth, health, production of "good" blood, life, and satisfaction of hunger. Participants in 3 FGs had knowledge of vitamin A and its deficiency diseases but only 2 FGs had knowledge of foods that can prevent vitamin A deficiency. Also, 23 FGs were aware of the occurrence of iron deficiency anaemia especially in pregnant women while 25 FGs mentioned the effects of anaemia such as dizziness, weakness and maternal deaths. However, only 8 FGs had knowledge of the causes of anaemia and in this case, they mentioned poor eating habits as a possible cause but could not associate it with any particular foods. Furthermore, all the FGs mentioned the use of haematinics in the treatment and prevention of anaemia but only 4 FGs knew about the use of food-based approaches.

\section{Participants' consumption practices in relation of vitamin $A$ and iron deficiency prevention foods}

Due to the limited knowledge of participants on foods for preventing vitamin A and iron deficiencies, the FG moderator discussed the Ghana's Ministry of Health and Anaemia Coordinating Committee's recommended food groups with the participants. Therefore, findings presented here were obtained after the moderator's intervention. The FGs participants mentioned various foods in each of the recommended food groups that are 


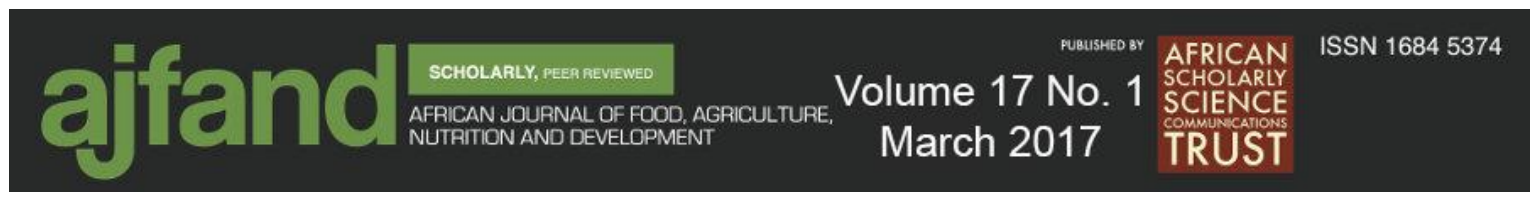

available in their communities. The list of foods is shown in Table 1 and it includes items mentioned by at least one person in a FG.

\section{Availability and consumption practices in relation to animal products}

In all the communities, game (bush meat), frozen poultry, and fish were usually consumed. Barriers that affect availability and consumption of animal products are presented in Table 2, where $80 \%$ of the FGs mentioned lack of storage facilities, irregular supply (68\%), lack of money $(64 \%)$ and conflicting media reports on effects of meat consumption (84\%) as barriers. Other barriers were distant market centres, social status, lack of knowledge and skill on animal and fish production, theft, superstition, and traditional food culture. Communities without electricity get their fish supplies weekly or fortnightly through delivery vans and from weekly market centres. Access to fish in such communities is a challenge because of inadequate money to buy the fish in bulk for use until the next supply. Some participants (about 90\%) felt that consumption of smoked-dried anchovies (Keta school boys or nsesaawa) was associated with lower social status or poverty. Furthermore, in Abidjan community, the Agricultural Extension Agents confirmed that some persons were trained in aquaculture and were even practising it but the major challenge was theft. It was also realized that River Bia in Antwiagyeikrom and another river in Akwaaduro had fishes in them but participants would not harvest them due to lack of requisite skills and superstition. Interestingly, participants were of the view that they cannot challenge the gods so superstitious issues are beyond their control.

The importance of media was also mentioned with participants indicating they had often heeded to the repeated messages on radios to limit meat and egg consumption. Also, in most households, adult males were often given large portions of meat while vulnerable groups such as children and adolescent girls took less or none at all.

\section{Availability and consumption practices in relation to vegetables}

In all the communities, kontomire (cocoyam leaf) was readily mentioned among the dark green leafy vegetables (DGLV) because it is readily available. Upon further probing, other green leafy vegetables were mentioned including alefu (amaranthus), ayoyo (Corchorus olitorius), sweet potato, cassava and moringa leaves as shown in Table 1. Some of the vegetables grow in the wild while others are produced in homestead gardens. Findings revealed that garden eggs, kontomire (cocoyam leaves), and kwansusua (Solanum sp.) were largely consumed in all the communities. Other vegetables were minimally consumed. It was found that both districts were endowed with lots of foods that can prevent vitamin A and iron deficiencies but their consumption levels have been reportedly declining over the years as demonstrated in the following quotes:

"Lactating mothers are given meals prepared with a variety of vegetables including DGLV to enable them replace blood that might have been lost during childbirth. Sadly however, the practice stops by six months after delivery" (A woman, about 35 yrs).

"In present times our wives most often prepare soups with only tomato paste, pepper and artificial flavour enhancers. As a result, most of us, although less 


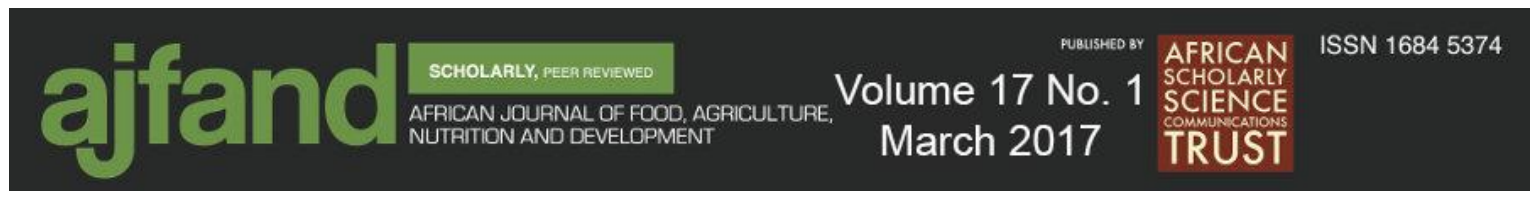

than 50 years, experience a number of health problems including frequent waste pains" (A man, Chairman of one Cocoa Cooperative).

Participants who frequently consumed DGLV gave testimonies about the benefits they have derived from them as shown in the following narratives:

"I have been eating leafy vegetables on regular basis from my infancy and, as a result, I hardly fall ill" (A middle-aged woman).

"I used to eat lots of DGLV and was healthy but for the past six years, since I moved in to live with my daughter, I have been denied these vegetables and I have often been ill as a result" (An elderly woman recounted).

To reaffirm these narratives an Assemblywoman also recounted:

"I use 24 different leaves for food preparation and these have protected me and my family from lots of diseases" (to ascertain her narrative, she rushed to her garden nearby and brought some of the leaves to show to all the participants).

A number of participants observed that people of Northern extraction who live in the communities hardly fall ill and usually live longer. This, they said, was attributable to the high consumption of DGLVs among the northern tribes. Despite this, most people would not eat such vegetables because of unwillingness to cross ethnic boundaries in their diet and consume unfamiliar foods.

Barriers to the availability and consumption of vegetables are summarised in Table 2 and they included inadequate knowledge on edibility and food uses of some vegetables as reported in $96 \%$ of the FGs, laziness (56\%), non-palatability of some vegetables $(64 \%)$, inadequate preparation and cooking skills (64\%), and agro-chemical contamination $(96 \%)$. A few of the participants volunteered to describe how some of the DGLV could be used in food preparation for the benefit of those who did not know and it was revealed that the vegetables were sometimes inappropriately prepared and stored, which could result in the loss of nutrients. For example, from the descriptions given, kontomire is usually boiled and the stock, which may contain water soluble vitamins, is discarded. Also, some families prepare soups in bulk but due to the lack of electricity or refrigerators they resort to repeated re-heating, which can potentially lead to further destruction or loss of micronutrients. Participants also indicated that exotic vegetables such as cabbages, carrots, and lettuce were available in the communities but it was realized that these vegetables were mostly cultivated for commercial purposes hence they were rarely eaten at home.

\section{Availability and consumption practices in relation to fruits and legumes}

Fruits were largely available in all the communities but most participants confessed that they usually do not eat them. Oranges, for instance, could get rotten on the farms because of low consumption and lack of market opportunities. The main reason for the low consumption of fruits as indicated by $92 \%$ of the FGs was due to the traditional Ghanaian food culture where fruits are not considered as food or part of the meal. Thus participants had not cultivated the habit of eating fruits with meals. The seasonal availability of fruits, which was mentioned in $95 \%$ of the FGs, also contributed to low consumption - when 


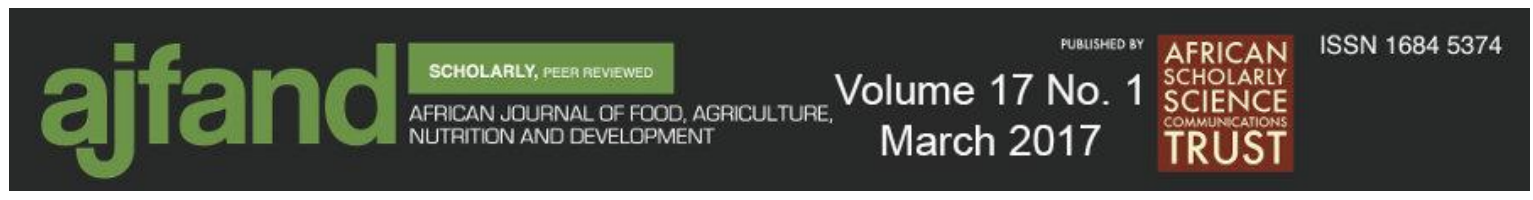

fruits are in season, consumption is higher although they are often not eaten as part of the meal. Other barriers as shown in Table 2 included lack of knowledge on the nutritional value of fruits $(72 \%)$, laziness in washing and peeling (60\%), and contamination with agrochemicals $(80 \%)$.

Legumes, such as groundnuts, agushi (melon seed), and beans (cowpeas and other varieties), were available in most communities but their consumption was quite low. In about $48 \%$ of the FGs, participants perceived the oil in groundnut soup as the cause of jaundice; hence, they avoid eating groundnut soups. Other barriers to legume consumption as shown in Table 2 were inadequate knowledge of their nutritive value $(64 \%)$ and limited availability due to low production $(48 \%)$.

\section{Participants' suggested actions at the individual, community and governmental levels}

Based on the focus group discussions, participants suggested certain actions that may be implemented at the individual, community and governmental levels to facilitate increased availability and consumption of foods that can prevent vitamin A and iron deficiencies as shown in Table 3. For animal products, 22 FGs suggested that all people must ensure their children, adolescents and pregnant women eat more meat/fish, 20 FGs suggested re-prioritisation of their expenditure to give prominence to animal source protein while 10 FGs proposed to learn and practice aquaculture. To increase vegetable availability and consumption, 23 FGs called for the need to learn to acquire vegetable cooking skills, all the 25 FGs said they would spread the message about benefits of vegetables and cultivate them, and 19 FGs said they would frequently eat leafy vegetables since they have learnt of their nutritional values at the FG discussions. For fruits, 19 FGs suggested that they would always serve fruits at mealtimes and ensure that children in particular eat them until it becomes their habit while 11 FGs indicated they would pick fruits from farms for family members and neighbours. To increase legumes availability and consumption, 21 FGs proposed to educate family members on the benefits of legumes while 17 FGs said they would cultivate and eat more beans especially cowpeas and soybeans. Also, at the community and governmental levels, the proposed actions to increase the availability and consumption of vitamin A and iron deficiency prevention foods included provision of infrastructure such as roads and markets, public education and training as indicated in Table 3.

\section{DISCUSSION}

The objective of this study was to assess the knowledge and consumption practices of members of rural communities in relation to vitamin $\mathrm{A}$ and iron deficiencies and to suggest individual, community and governmental level actions that may facilitate the adoption of the recommended food-based approaches.

Generally, participants lacked knowledge on vitamin A, its deficiency diseases and foodbased approaches to its prevention. However, they knew of iron deficiency anaemia especially in pregnant women and attributed its causes to poor eating habits. Participants were quick to mention the use of haematinics in preventing and treating anaemia but had inadequate knowledge on the food-based approaches. These findings suggest that 


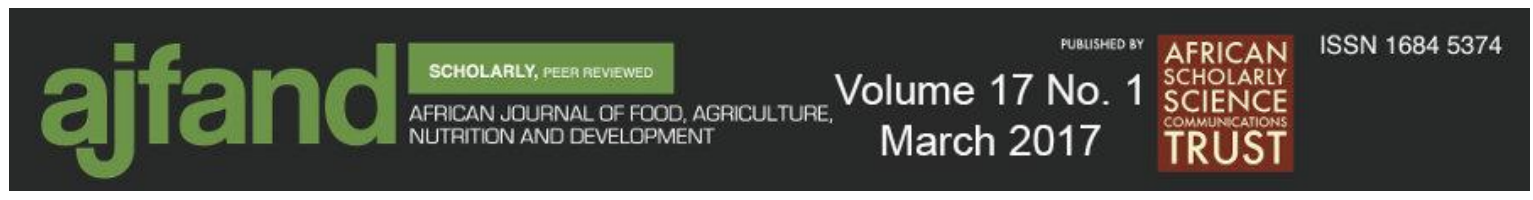

although vitamin A and iron deficiencies are important public health concerns in Ghana, awareness and knowledge about them is low in rural communities. It is, therefore, important to incorporate education and awareness creation when implementing interventions because they can influence individual consumption practices and behaviours. These findings also call for more emphasis on food-based approaches as preventive methods for these micronutrient deficiencies.

The study identified various foods (animal, vegetable, fruit and legume based food groups) that are useful for preventing iron and vitamin A deficiencies. Kontomire (cocoyam leaves), which was readily mentioned in all the communities, is a better source of $\mathrm{Fe}, \mathrm{K}, \mathrm{Mg}$ and $\mathrm{Zn}$ compared with alefu and ayoyo, while moringa and sweet potato leaves are richer in nutrients than cassava leaves and alefu $[18,19]$. Lots of similarities were found in the foods in the communities probably because both districts lie in the same ecological zone and participants were largely of the Akan ethnic group with a common food culture. It is possible to find some differences in the available foods if a similar study is conducted in other parts of Ghana.

Although various vitamin A and iron deficiency prevention foods were available in the communities, their consumption has been dwindling over the years due to factors such as lack of knowledge about the nutritional value, lack of cooking skills, low production levels, laziness and cultural beliefs. Findings showed that access to fish and meat is hindered by lack of cold storage facilities due to unavailability of electricity and inadequate money. This implies that there is need to encourage rural communities to adopt other meat and fish preservation methods such as drying and smoke-drying and to prioritize expenditures so that adequate funds are allocated for the purchase of animal source protein. The reluctance to consume fish from some rivers due to superstition showed that people's beliefs and perceptions can influence access and consumption of certain foods. Therefore, continuous sensitisation is needed to minimise the negative effects of such beliefs. Barriers such as limited recipes, laziness, dislike for taste of vegetables and chemical and microbial contamination have also been identified in some studies to reduce vegetable consumption [20,21, 22].

The role of the media, particularly radio, in delivering nutrition messages in rural communities was manifested in the study but the challenge is the development of targeted messages for various audiences such as urban and rural dwellers, the rich and the poor, children and adults and so on. For example, although rapid urbanization and economic improvements have generally resulted in more meat consumption, animal protein consumption in rural areas is still low, which accounts for the high prevalence of iron deficiency anaemia. For this reason, it may be inappropriate to advise rural dwellers to avoid or reduce animal product intake. Studies have even shown that typical traditional Ghanaian diets are largely composed mostly of staple carbohydrates, with little protein and minimal vegetables [23, 24]. Findings from this study suggest that people are receiving conflicting nutrition messages, which potentially leads to confusion. Therefore, nutrition educators need to use the media and other channels to conduct targeted education and to clearly define the target audience and tailor messages to meet the audience's needs. For example, in rural communities, people need iron but also need to 


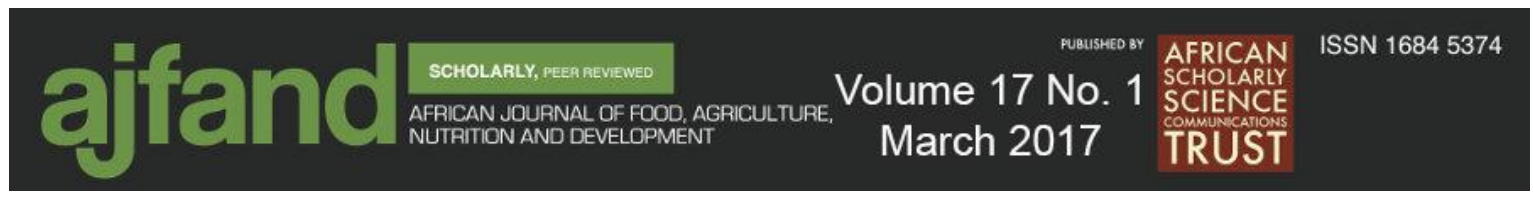

minimise the consumption of animal fat; therefore, educational messages may emphasize the preparation and consumption of lean meats as much as possible.

The findings suggest that the adoption of healthy consumption behaviour is promoted by decreasing the barriers connected with performing the behaviour [25] and that interventions that seek to reduce the incidences of vitamin $\mathrm{A}$ and iron deficiencies should adopt strategies that will facilitate increased consumption of the recommended foods. Firstly, vulnerable individuals need to be encouraged to take actions, which include learning new cooking skills, cultivating more of the recommended foods, and prioritising spending to ensure adequate allocation of money for buying the "right" foods. Secondly, government institutions such as the Ministry of Food and Agriculture, Ministry of Health, civil society organizations, and others need to take some actions including: (1) training communities on vegetable production and providing them with appropriate seeds; (2) revisiting and promoting the home-gardening concept to increase the availability of vegetables in all households; (3) training Agricultural Extension Agents and giving them resources to train farmers on safe use of agrochemicals on food crops, particularly vegetables; (4) developing and documenting recipes for vegetable dishes; (5) incorporating vegetables and fruits into school meals; (6) training women and others on appropriate cooking methods that will conserve nutrients; and (7) promoting animal production and aquaculture to increase availability of protein and iron-rich foods.

The authors, however, acknowledged that nutrition education alone may not necessarily lead to changes in practices hence governments and other agencies need to support healthy behaviours and practices and when necessary, provide incentives for the adoption of healthy practices. Implementing these requires effective communication tools such as the Communication for Behavioural Impact (COMBI) technique and a sustained financial commitment to support the adoption of healthy nutritional practices.

\section{CONCLUSION}

This study showed that foods that can prevent vitamin A and iron deficiencies are available in rural cocoa-producing areas; however, consumption of these foods is low due to certain barriers that have been identified. Consequently, interventions should focus on strategies that can remove these barriers to enhance the consumption of the recommended foods.

\section{ACKNOWLEDGEMENTS}

This work was made possible by Cadbury Cocoa Partnership Programme, which provided funds, Care International (Ghana, Kumasi), which facilitated the work and EatSafe Ghana, which conducted the nutrition education and the study. 


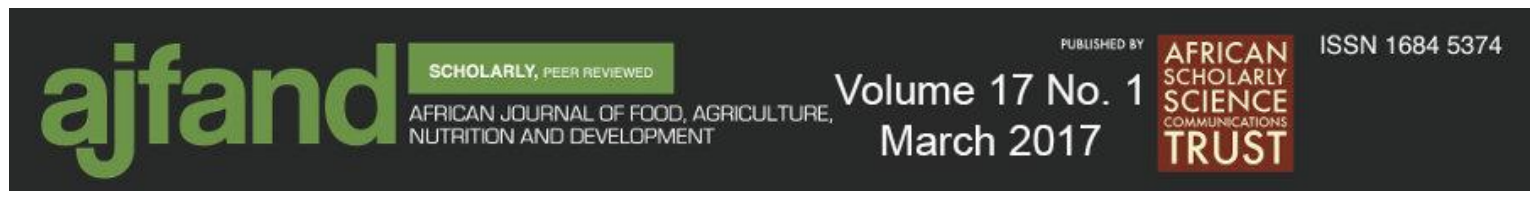

Table 1: Foods for the prevention of vitamin $A$ and iron deficiencies available in the communities

\begin{tabular}{llll}
\hline Animal products & Vegetables & Fruits & Legumes \\
\hline Game (bush meat) & Kontomire (Cocoyam leaves) & Pear & Cowpeas \\
Amane (smoked dried & Honhon* & Pineapple & Beans (various \\
Herrings) & Ayoyo (Corchorus olitorius) & Banana & varieties) \\
Sardinella & Fortor* & Orange & Soybeans \\
Koobi (salted dried & Nsusua (Solanum sp.) & Pawpaw & Groundnuts \\
tilapia) & Kokoo ahahan (Cocoa leaves) & Sweet apple & Agushi (Melon \\
Goat & Edua ahahan (Cowpea leaves) & Mango & seeds) \\
Nsesaawa (Anchovies) & Nkruma (Okro) & Watermelon & \\
Ngwa (Snails) & Tomatoes & Guava & \\
Salmon & Bankye Ahahan (Cassava leaves) & Tangerine & \\
Kpala & Nyaadoa (Garden eggs) & Apple & \\
Antelope & Onyina ahahan* (leaves of Silk & & \\
Crab & Cotton, Ceiba Pentandra) & & \\
Herrings & Wawa ahahan* (leaves of & & \\
& Triplochiton scleroxylon) & & \\
& Alefu (Amaranthus) & \\
& Dandelion & & \\
& Moringa & & \\
& Sweet potato leaves & & \\
& Cabbage & & \\
& Carrot & & \\
& Lettuce & & \\
\hline
\end{tabular}

* Leafy vegetables that grow in the wild 


\section{ajfand}

Table 2: Barriers to the consumption of vitamin A and iron deficiency prevention foods

\begin{tabular}{|c|c|c|c|c|}
\hline \multirow[t]{2}{*}{ Food group } & \multirow[t]{2}{*}{ Barrier } & \multicolumn{2}{|c|}{ Number of focus groups $(\mathrm{N}=25)^{*}$} & \multirow[t]{2}{*}{$\%$ of focus group or communities } \\
\hline & & Ashanti Region $(\mathrm{N}=11)$ & Brong Ahafo Region $(\mathrm{N}=14)$ & \\
\hline \multirow[t]{10}{*}{ Animal product } & Lack of storage facilities & 8 & 12 & 80 \\
\hline & Irregular supply & 6 & 11 & 68 \\
\hline & Distant market centres & 8 & 13 & 84 \\
\hline & Lack of money & 9 & 7 & 64 \\
\hline & Identity (social status) & 4 & 8 & 48 \\
\hline & Lack of knowledge and skill on animal and fish production & 5 & 9 & 56 \\
\hline & Theft & 5 & 5 & 40 \\
\hline & Superstition & 1 & 3 & 16 \\
\hline & Traditional food culture & 7 & 9 & 64 \\
\hline & Conflicting media reports on meat consumption & 9 & 12 & 84 \\
\hline \multirow{13}{*}{ Vegetables } & Lack of knowledge on edibility and food uses of some vegetables & 11 & 13 & 96 \\
\hline & Lack of motivation to cultivate & 7 & 9 & 64 \\
\hline & Too much focus on commercial vegetable production & 8 & 6 & 56 \\
\hline & Inadequate preparation and cooking skills & 6 & 10 & 64 \\
\hline & Preparation of vegetable is time-consuming & 9 & 11 & 80 \\
\hline & Vegetable soups consumption perceived as 'old fashioned' among younger generations & 9 & 7 & 64 \\
\hline & Laziness & 6 & 8 & 56 \\
\hline & Lack of knowledge on the nutritional value of vegetables & 10 & 8 & 72 \\
\hline & Non-palatability of some vegetables- some have varied degrees of bitterness & 7 & 9 & 64 \\
\hline & Belief that imported (processed) foods are better than local food & 8 & 10 & 72 \\
\hline & Influence of adverts on processed foods, e.g. tomato paste, flavour enhancers & 9 & 8 & 68 \\
\hline & Extensive use of herbicides destroys most DGLV that grow in the wild & 9 & 10 & 80 \\
\hline & Excessive use and wrong choice of agrochemicals on vegetables & 10 & 14 & 96 \\
\hline \multirow[t]{6}{*}{ Fruits } & Traditional Food culture, e.g., fruits not considered as food & 11 & 12 & 92 \\
\hline & Seasonal availability & 10 & 14 & 95 \\
\hline & Lack of knowledge of nutritional value & 8 & 10 & 72 \\
\hline & Laziness (e.g., in peeling) & 6 & 9 & 60 \\
\hline & Lack of storage facilities & 5 & 8 & 52 \\
\hline & Contamination with agro-chemicals & 8 & 12 & 80 \\
\hline \multirow[t]{4}{*}{ Legumes } & Fear of allergic reactions e.g. jaundice & 7 & 5 & 48 \\
\hline & Lack of knowledge of their nutritive value & 9 & 7 & 64 \\
\hline & Limited availability due to low production & 5 & 7 & 48 \\
\hline & Fear of developing pimples & 8 & 4 & 48 \\
\hline${ }^{*}$ At least two pers & mentioned this as a barrier at each of the & reen leafy vegetables & & \\
\hline
\end{tabular}




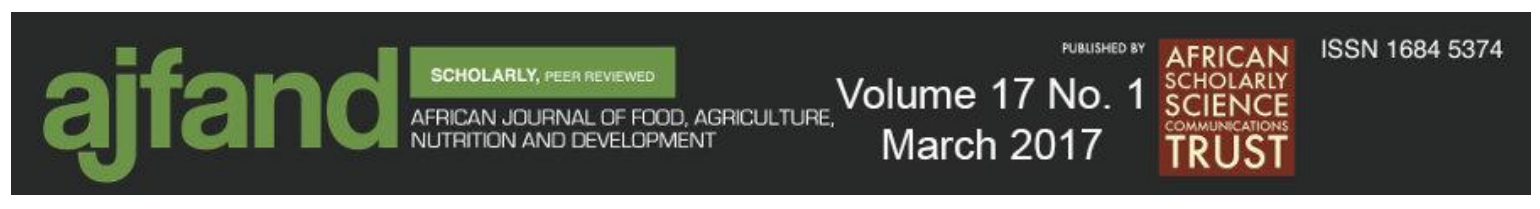

Table 3: Suggested individual, community and government actions for increased consumption of animal products, vegetables, legumes and fruits

\begin{tabular}{|c|c|}
\hline Food group & $\begin{array}{l}\text { No of Focus } \\
\text { Group* }\end{array}$ \\
\hline \multicolumn{2}{|l|}{ INDIVIDUAL ACTIONS } \\
\hline \multicolumn{2}{|l|}{ Animal products } \\
\hline Adopt other methods of preservation & 16 \\
\hline Buy in bulk if possible & 8 \\
\hline Prioritize expenditure- make animal protein a top priority & 20 \\
\hline Consider no animal products as inferior or valueless & 6 \\
\hline Learn and practice aquaculture and fishing & 10 \\
\hline Be each other's keeper and guard against theft & 4 \\
\hline Ensure children, adolescents and pregnant women eat more meat/fish & 22 \\
\hline \multicolumn{2}{|l|}{ Vegetables } \\
\hline Learn to acquire cooking skill from the elderly, community members and other trainers & 23 \\
\hline Spread the message about benefits of vegetables and cultivate vegetables & 25 \\
\hline Produce vegetables for both commercial and home consumption & 18 \\
\hline Start preparing food early so that we can have enough time to prepare the vegetables & 15 \\
\hline Cook the vegetables often and ensure that children eat and get used to them & 14 \\
\hline Encourage and help one another in the communities & 9 \\
\hline Husbands will pick vegetables from farms for their wives & 16 \\
\hline Frequently eat leafy vegetables now that we know their values & 19 \\
\hline Learn how to improve on the taste & 12 \\
\hline Start cultivating and eating more fresh and natural vegetables and herbal-based spices & 14 \\
\hline Stop destroying leafy vegetables with herbicides & 9 \\
\hline
\end{tabular}




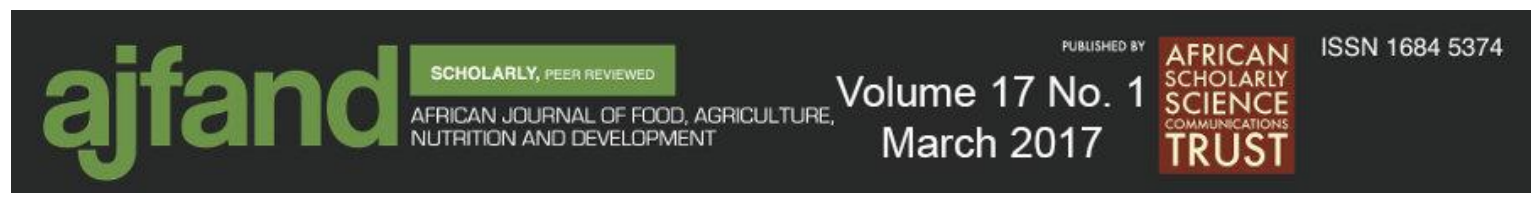

Cultivate vegetable gardens

13

Advise vegetable farmers to learn about pesticide usage

Fruits

Always serve fruits at mealtimes and ensure that children in particular eat them until it becomes their habit 19

Frequently eat whichever fruit is in season

Educate children and families on the benefits of fruits and ensure that we eat them daily

Encourage and help one another in the communities

Pick fruits from farms for family members and neighbours

9

Ensure that fruits are washed and peeled before selling/eating

Legumes

Educate family members on the benefits of legumes

Cultivate and eat more beans especially cowpeas and soybeans

COMMUNITY/GOVERNMENTAL ACTIONS

Animal products

Provide infrastructure (e.g. electricity, roads, community markets) 16

Conduct public education

Promote animal production and aquaculture

24

Provide community watchdogs

10

Vegetables

Public education with demonstrations

5

Train communities on vegetable production and provide them with seeds

25

Develop and document vegetable recipes

18

Train women and others on vegetable recipes and proper cooking methods that will conserve as many nutrients as possible

Incorporate vegetables into school meals

24

12

Develop innovative recipes to enhance palatability

10

Regulate the content of adverts

Promote local spices and condiments 


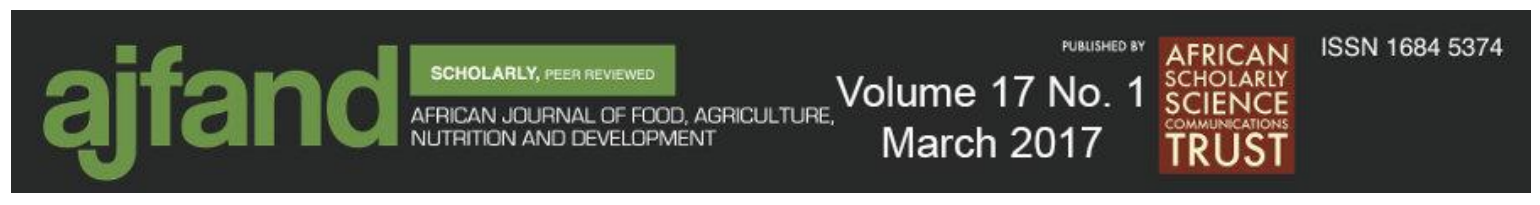

Promote consumption of locally produced foods 15

Revisit the home gardening concept

4

Train Agricultural Extension Agents and give them resources to train farmers on safe use of agrochemicals

Fruits

Incorporate fruits into school meals

Introduce all-year-round fruit varieties

13

Educate the public on benefits of fruit consumption

22

Educate farmers and the entire community on appropriate use of agro-chemicals and food safety in general

Provide incentives, irrigation facilities and other infrastructure such as electricity and roads

Legumes

Promote production and consumption of legumes

Supply improved seeds to farmers

(1)

8

*At least two persons mentioned this as a barrier at each of these focus group discussions 


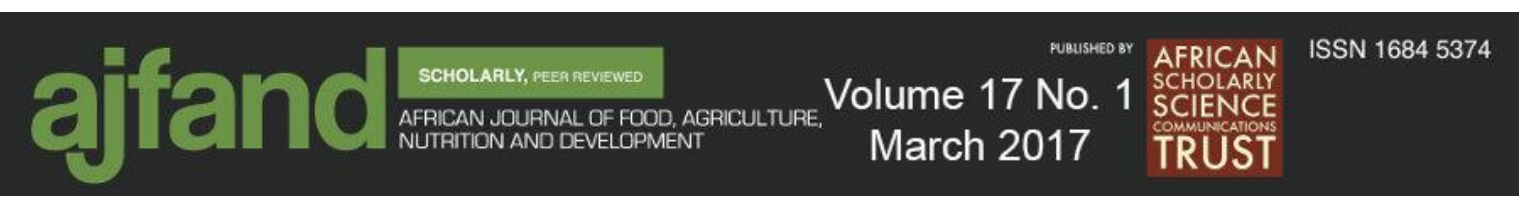

\section{REFERENCES}

1. FAO. United Nations Food and Agriculture Organization. The Nutrition Profile for the Republic of Ghana. Nutrition and Consumer Protection Division, FAO, Rome, 2009.

2. Ghana Health Service. National Anaemia Control Strategy. Ghana Health Services, Nutrition Unit, Accra, Ghana, 2008.

3. Ghana Statistical Service, Noguchi Memorial Institute for Medical Research, and ORC Macro. Ghana Demographic and Health Survey 2003. GSS, Accra, NMIMR, Accra, and ORC Macro, Calverton, Maryland, 2004.

4. WHO. United Nations World Health Organization. Indicators for assessing vitamin A deficiency and their application in monitoring and evaluating intervention programmes. WHO/NUT/96.10. WHO, Geneva, Switzerland, 1996.

5. Ghana Statistical Service, Ghana Health Service, and ICF Macro. Ghana Demographic and Health Survey (2008): Key Findings. GSS, GHS, and ICF Macro Calverton, Maryland, USA. 2009.

6. Alderman H, Hoddinott $\mathbf{J}$ and B Kinsey Long term consequences of early childhood malnutrition. Oxford Economic Papers. 2006; 58(3): 450-474.

7. Ghana Statistical Service. The 2014 Ghana Demographic and Health Survey: Key Indicators, 2015. Available from http://www.statsghana.gov.gh/docfiles/publications/Ghana\%20DHS\%202014\%20\%20KIR\%20-\%206\%20April\%202015.pdf [Accessed Date: September 10, 2016].

8. McClafferty B and Y Islam Fighting the Hidden Hunger, 2008. Available from http://www.maff.go.jp/e/ccasia/18/pdf/ifpri.pdf [Accessed Date: May 10, 2016].

9. Ghana Statistical Service, Ministry of Health, UNICEF Ghana, USAID and Macro International. Ghana Multiple Indicator Cluster Survey 2006 (MICS) - Monitoring the situation of children, women and men. GSS, MoH, UNICEF Ghana, USAID, and Macro International. 2007; Available from:

http://www.childinfo.org/files/MICS3_Ghana_FinalReport_2006.pdf- [Accessed Date: November 27, 2014].

10. FAO. United Nations Food and Agriculture Organization. Food-based nutrition strategies in Bangladesh: Experience of integrated horticulture and nutrition development. FAO, Regional Office for Asia and the Pacific. Bangkok; Thailand, 2007; Available from: ftp://ftp.fao.org/docrep/fao/010/ag126e/ag126e_full.pdf [Accessed Date: March 10, 2015]. 


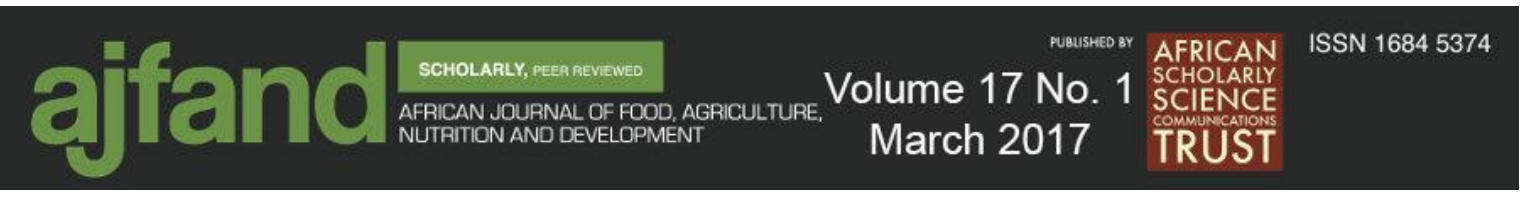

11. Tchum S, Newton S, Tanumihardjo S, Fareed K, Tetteh A and S Agyei Evaluation of a green leafy vegetable intervention in Ghanaian postpartum mothers. Afr. J. Food Agric. Nutr. Dev. 2009; 9 (6): 1294 - 1308.

12. Hotz C, Loechl C, de Brauw A, Eozenou P, Gilligan D, Moursi M, Munhaua B, van Jaarsveld P, Carriquiry A and JV Meenakshi A large-scale intervention to_introduce orange sweet potato in rural Mozambique increases vitamin A intakes among children and women. British Journal of Nutrition, 2012; 108(1): 163-176.

13. Meenakshi JV, Johnson N, Manyong V, De Groote H, Javelosa J, Yanggen D, Naher F, Gonzalez C, Garcia J and E Meng How cost-effective is biofortification in combating micronutrient malnutrition? An ex-ante assessment. HarvestPlus Working Paper No. 2, 2007. Available from:

http://siteresources.worldbank.org/EXTHDOFFICE/Resources/5485726-

1239047988859/5995659-1239051886394/HarvestPlus_Working_Paper2.pdf [Accessed Date: May 07, 2016].

14. Ghana Health Service. Nutrition and Malaria Control for Child Survival Project: Project Background Report. Ghana Health Service. Accra; Ghana, 2011; Available from: http://www.ghanahealthservice.org/nmccsp.php [Accessed Date: November 27, 2014].

15. European Commission. Consumer behaviour: the road to effective policy-making. 2012. Available from http://ec.europa.eu/consumers/docs/1dg-sanco-brochure-consumerbehaviour-final.pdf [Accessed Date: January 20, 2013].

16. Bryman A Social Research Methods. Oxford: Oxford University Press, 2004.

17. Clarke A Research and the policy-making process. In: Gilbert N (ed). Researching Social Life. New Delhi: Sage Publications, 2001.

18. Amagloh FK and ES Nyarko Mineral nutrient content of commonly consumed leafy vegetables in northern Ghana. Afr. J. Food Agric. Nutr. Dev. 2012; 12 (5): 6397-6408.

19. Oduro I, Ellis W and D Owusu Nutritional potential of two leafy vegetables: Moringa oleifera and Ipomoea batatas leaves. Sci. Res. Essays. 2008; 3 (2): 057-060.

20. John JH and S Ziebland Reported barriers to eating more fruit and vegetables before and after participation in a randomized controlled trial: a qualitative study. Health Educ. Res. 2004; 19 (2): 165-174.

21. Lucan SC, Barg FK and JA Long Promoters and barriers to fruit, vegetable, and fastfood consumption among urban, low-income African Americans - A qualitative approach. Am J Public Health. 2011; 100 (4): 631-635. 


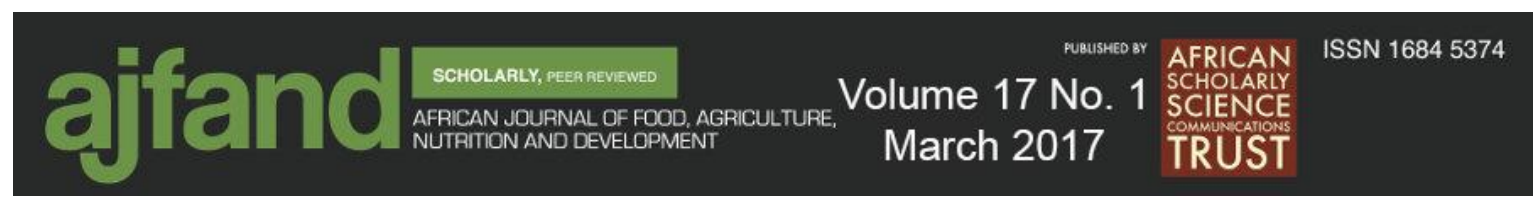

22. Haynes-Maslow L, Parsons SE, Wheeler SB and LA Leone A qualitative study of perceived barriers to fruit and vegetable consumption among low-income populations, North Carolina, 2011. Prev Chronic Dis. 2013; 10 (March). DOI: http://dx.doi.org/10.5888/pcd10.120206.

23. Asiedu M, Abankwa SK and AK Anderson Nutritional evaluation of fast foods in Accra. Proceedings of the $9^{\text {th }}$ Faculty of Science Colloquium, University of Ghana, Accra, Ghana, 1999.

24. Omari R, Jongerden JP, Essegbey G, Frempong G and GTP Ruivenkamp Fast food in the Greater Accra Region of Ghana: Characteristics, availability and the cuisine concept. Food Studies. 2013; 1 (4): 29-44.

25. WHO. United Nations World Health Organization. Manual for planning communicationfor-behavioural-impact (COMBI) programmes for health. Communicable Diseases (CDS) Division WHO Mediterranean Centre for Vulnerability Reduction, Geneva/Tunis, 2006. 